\title{
FT-IR spectroscopy supported by PCA-LDA analysis for the study of embryonic stem cell differentiation
}

\author{
Diletta Ami ${ }^{\mathrm{a}}$, Antonino Natalello ${ }^{\mathrm{a}}$, Paolo Mereghetti ${ }^{\mathrm{b}}$, Tui Neri ${ }^{\mathrm{c}}$, Mario Zanoni ${ }^{\mathrm{c}}$, \\ Manuela Monti ${ }^{\mathrm{d}}$, Silvia Maria Doglia ${ }^{\mathrm{a}, *}$ and Carlo Alberto Redi ${ }^{\mathrm{c}, \mathrm{d}}$ \\ ${ }^{a}$ Dipartimento di Biotecnologie e Bioscienze, Università di Milano-Bicocca, Milano, Italy \\ ${ }^{\mathrm{b}}$ BIOMS (Center for Modeling and Simulation in the Biosciences), University of Heidelberg, \\ Heidelberg, Germany and Molecular and Cellular Modelling Group, EML Research GmbH, \\ Heidelberg, Germany \\ ${ }^{\mathrm{c}}$ Laboratorio di Biologia dello Sviluppo, Dipartimento di Biologia Animale, Università degli Studi di \\ Pavia, Pavia, Italy \\ ${ }^{\mathrm{d}}$ Fondazione IRCCS Policlinico San Matteo, Pavia, Italy
}

\begin{abstract}
As recently pointed out in the literature, Fourier transform infrared (FT-IR) spectroscopy is emerging as a powerful tool in stem cell research. In this work we characterized in situ by FT-IR microspectroscopy the differentiation of murine embryonic stem cells (ES) to monitor possible changes in the cell macromolecular content during the early stages of differentiation. Undifferentiated and differentiating cells at 4, 7,9 and 14 days were measured. Data were analyzed by the principal component and subsequent linear discriminant analyses (PCA-LDA) that enabled us to segregate ES cell spectra into well separate clusters and to identify the most significant spectral changes. Important changes in the lipid $\left(3050-2800 \mathrm{~cm}^{-1}\right)$, protein $\left(1700-1600 \mathrm{~cm}^{-1}\right)$ and in the nucleic acid $\left(1050-850 \mathrm{~cm}^{-1}\right)$ absorption regions were observed between days 4 to 7 of differentiation, indicating the appearance - at day 7 - of the new phenotype into cardiomyocyte precursors. Also the presence of DNA/RNA hybrid bands $\left(954 \mathrm{~cm}^{-1}\right.$ and $\left.899 \mathrm{~cm}^{-1}\right)$ suggests that the transcriptional switch of the genome started at this stage of differentiation. Particularly noteworthy, we suggest that the $2936 \mathrm{~cm}^{-1}$ shoulder we observed could reflect methyl group vibrations thus allowing the detection of variations in methylation levels of the stem cell during differentiation. These infrared results were found to be in agreement with the biochemical characterization of these differentiating cells, underlying the great potential of FT-IR spectroscopy in stem cell research.
\end{abstract}

Keywords: FT-IR microspectroscopy, stem cell differentiation, multivariate PCA-LDA, cardiomyocytes, nucleic acids, methyl groups, proteins, lipids

\section{Introduction}

Embryonic stem (ES) cells are self-renewing and pluripotent cells that derive from the inner cell mass of the mammalian blastocyst [25]. Since ES cells, when properly stimulated, are able to differentiate

\footnotetext{
* Corresponding author: Silvia Maria Doglia, Department of Biotechnology and Biosciences, University of Milano-Bicocca, Piazza della Scienza 2, 20126 Milano, Italy. Tel.: +39 02 64483461; E-mail: silviamaria.doglia@ unimib.it.
} 
into any cell type, they can have therapeutic and pharmaceutical applications for instance in tissue engineering and drug screening in a wide range of therapies [17].

To better understand the ES cell physiology and to exploit their therapeutic potential, it is crucial to identify the molecular markers that regulate the differentiation process and that can be used to predict the fate of cell lineages. To this goal, vibrational spectroscopies - Raman and Fourier transform infrared spectroscopies - have been successfully applied $[4,8,13,16,19-21,28]$ beside the conventional molecular biology and biochemical techniques. Indeed, these optical approaches allow to detect in situ changes in the macromolecular content of whole cells, without any labeling of the sample, therefore providing a unique molecular fingerprint.

In particular, FT-IR spectroscopy has emerged in the last decades as a powerful technique not only for the study of purified biomolecules [5,6], but also for the study of intact cells [2-4], tissues [9] and whole organisms [1].

We applied FT-IR microspectroscopy $[19,22,27]$ - supported by multivariate analysis of the data to monitor spontaneous murine ES cell differentiation [4]. The use of principal component and linear discriminant analyses (PCA-LDA) [11,29] allowed to identify, during differentiation, the significant spectral variations that were assigned to specific molecular events through the support of biological assays. Important changes of the nucleic acid and protein content occurred during the differentiation process. Interestingly, also significant variations in the protein secondary structure were observed at the rising of the new phenotype.

In this work we report the results of our previous FT-IR study on murine ES cell differentiation [4], adding new insights on lipid modifications occurring during the first stages of this biological process. Moreover, we will describe in more details the multivariate analysis procedure, which is crucial to validate the spectroscopic results.

\section{Materials and methods}

\subsection{ES cell culture}

ES cell culture was performed as previously described ([4] and references therein). Briefly, before FTIR measurements, undifferentiated murine ES cells were cultured for 3 passages on T75 gelatin-coated flasks in a complete medium, to avoid STO contamination.

To induce spontaneous differentiation, colonies were dissociated to a single cell suspension and plated on new T75 gelatin-coated flasks in a leukemia inhibitory factor (LIF)-free ES medium that was changed every 2 days. Following plating, differentiated ES cells were collected and prepared for FT-IR analysis at days 4, 7, 9 and 14. Three independent experiments were carried out.

\subsection{FT-IR microspectroscopy}

FT-IR absorption spectra of murine embryonic stem cells undifferentiated and at different stages of differentiation were collected - from 4000 to $600 \mathrm{~cm}^{-1}$ - using a UMA 500 infrared microscope equipped with a nitrogen cooled MCT detector (narrow band, $250 \mu \mathrm{m}$ ) and coupled to a FTS-40A spectrometer (both from Bio-Rad, Digilab Division, MA, USA).

For the infrared measurements, cells were washed three times in a $0.9 \% \mathrm{NaCl}$ aqueous solution, in order to eliminate medium contamination. The cell suspension (about $3 \mu \mathrm{l}$ containing $\sim 10^{4}$ cells) was deposited onto a $\mathrm{BaF}_{2}$ window and dried at room temperature for $30 \mathrm{~min}$. 
Absorption spectra with an excellent signal to noise ratio (noise of $0.5 \mathrm{~mA}$ at $2000 \mathrm{~cm}^{-1}$ peak to peak) were acquired in transmission by setting the microscope diaphragm aperture at $100 \mu \mathrm{m} \times 100 \mu \mathrm{m}$, under the following conditions: $2 \mathrm{~cm}^{-1}$ spectral resolution, 128 scan coadditions, $20 \mathrm{kHz}$ scan speed and triangular apodization [22]. When necessary, spectra were corrected for residual water vapor absorption.

Second derivative spectra were obtained following the Savitsky-Golay method (3rd grade polynomial, 13 smoothing points), after a binomial 13 point smoothing of the measured spectra, using the GRAMS/32 software (Galactic Industries Corporation, USA).

In order to verify spectral reproducibility, we measured different areas of the same cell preparation and three independent experiments were performed. An excellent reproducibility both in band intensities and positions was found for each differentiation time - 0, 4, 7, 9 and 14 days.

\subsection{Multivariate analysis}

The statistical analysis of raw absorption spectra, and their first and second derivative spectra, was performed applying the principal component analysis and subsequent linear discriminant analysis (PCALDA), as described by Fearn [11]. In LDA, the ratio of the between-cluster variance to the within-cluster variance is maximized in forming the clusters. The main advantage of LDA is that it uses the classes information (i.e., differentiation time) in the derivation of clusters.

Using MatLab R2006a software (The Mathworks, USA) the spectral data were projected on the subspace defined by the eigenvectors of the covariance matrix and the PCA scores were first computed. These scores were then used as input for the subsequent LDA, where the class variable corresponded to the differentiation time. The selected eigenvectors of the PCA were obtained by iteratively repeating the PCA-LDA, increasing the number of eigenvectors starting from 2 up to the lowest number that corresponded to an associated variance of $100 \%$. In this way the highest classification accuracy was obtained. 25 eigenvectors were used for the raw data analysis, 23 for the first derivative and 22 for the second derivative spectra. In this last case, the first 3 PCA-LDA discriminant functions accounted for $92 \%$ of the explained variance in the $1800-800 \mathrm{~cm}^{-1}$ range, and for $95 \%$ in the lipid region, between 3050 and $2800 \mathrm{~cm}^{-1}$. The classification accuracy was evaluated from the fraction of correctly classified cases over the total examined ones. The leave-one-out validation was employed to obtain a robust accuracy estimation.

The most relevant wavenumbers that contribute to the inter-spectral variance were selected from the PCA-LDA loading matrix and from the total covariance matrix, as described in [4]. The obtained averaged loadings were rescaled in the range of values $0-1$ and those with values $\geqslant 0.80$ are reported in Table 1.

\section{Results and discussion}

The FT-IR absorption spectra of intact ES cells, undifferentiated and at different stages of differentiation up to 14 days, were obtained using an infrared microscope. Even if the infrared response of the ES cells is highly complex, the quality of the data was excellent, enabling us to perform the second derivative analysis of the spectra in order to better resolve the overlapped bands [26]. As described below, most of the changes were found in the protein $\left(1700-1500 \mathrm{~cm}^{-1}\right)$ and in the nucleic acid absorption (1050$870 \mathrm{~cm}^{-1}$ ) regions. Interestingly, also significant variations in the absorption region of the $\mathrm{CH}_{2}$ and $\mathrm{CH}_{3}$ 
Table 1

Marker bands of ES cell differentiation

\begin{tabular}{lccl}
\hline $\begin{array}{l}\text { Wavenumbers }\left(\mathrm{cm}^{-1}\right) \\
\text { from second derivative } \\
\text { spectra }\end{array}$ & \multicolumn{2}{c}{$\begin{array}{l}\text { Wavenumbers } \\
\text { from PCA-LDA }\end{array}$} & \multicolumn{1}{c}{ Assignment } \\
\cline { 2 - 3 } & $\mathrm{cm}^{-1}$ & Loading & \\
\hline $2852.6 \pm 0.1$ & 2849.2 & 0.85 & $\nu \mathrm{CH}_{2}$ symm, sensitive to hydrocarbon chain conformation [10,18] \\
$2923.1 \pm 0.3$ & 2915.7 & 1.00 & $\nu \mathrm{CH}_{2}$ symm, sensitive to hydrocarbon chain conformation [10,18] \\
$1656.7 \pm 1.3$ & 1658.0 & 0.80 & $\alpha$-helix protein secondary structure [6] \\
& 1656.1 & 1.00 & \\
$966.0 \pm 0.6$ & 962.6 & 0.80 & $\nu \mathrm{CC}$ of DNA backbone [5] \\
$954.5 \pm 1.0$ & 958.7 & 1.00 & $\nu \mathrm{CC}$ of DNA backbone [5] \\
& 954.9 & 0.90 & \\
\hline
\end{tabular}

Notes: Peak positions in the second derivative spectra of the marker bands of ES cell differentiation with their PCA-LDA loadings. Only loadings $\geqslant 0.80$ are reported.

acyl chain stretching modes $\left(3050-2800 \mathrm{~cm}^{-1}\right.$ ) were observed, suggesting that lipid modifications occur during the differentiation process.

\subsection{Protein changes during differentiation}

The FT-IR spectrum of undifferentiated cells in the protein absorption region of the $\mathrm{C}=\mathrm{O}$ carbonyl group of the peptide bond, from 1700 to $1600 \mathrm{~cm}^{-1}$ (Amide I band) [6], is characterized by three main components, assigned respectively to antiparallel $\beta$-sheet $\left(1692 \mathrm{~cm}^{-1}\right), \alpha$-helix $\left(1657 \mathrm{~cm}^{-1}\right)$ and intramolecular $\beta$-sheet $\left(1639 \mathrm{~cm}^{-1}\right)$ secondary structures. As shown in Fig. 1, the relative intensity of these components changes during the differentiation process, as expected considering the protein expression of the new phenotype. In particular, an increase of the $\alpha$-helix content together with the appearance of appreciable $\beta$-turn structures, around $1682 \mathrm{~cm}^{-1}$, is observed from days 4 to 7 . Interestingly, by the PAS reaction cytochemical analysis [15,24] performed in the same span of time, a population of cardiomyocyte precursors was detected [4]. Indeed, these differentiating cells are rich in alpha-myosin (an $\alpha$-helix protein) and are characterized by an increase, during differentiation, of gap junctions that contain connexins, again $\alpha$-helix proteins with an important percentage of $\beta$-turns [23]. Therefore, the significant increase in the protein infrared response of the $\alpha$-helix content and the appearance of the $\beta$ turn component allow to monitor in a rapid and easy way the ES cell differentiation into cardiomyocyte precursors, without any sample handling.

\subsection{Nucleic acid changes during differentiation}

Three principal bands were identified in the FT-IR nucleic acid absorption regions, between 1050 and $850 \mathrm{~cm}^{-1}$, of undifferentiated cells. They are respectively the $994 \mathrm{~cm}^{-1}$ (RNA ribose phosphate main chain mode), $966 \mathrm{~cm}^{-1}$ (likely due to the DNA CC stretching of the backbone) and the $914 \mathrm{~cm}^{-1}$ (RNA ribose ring mode) bands [5]. During ES cell differentiation these components vary in intensity and peak positions, as shown in Fig. 1. As differentiation started, an important decrease of these bands - that represent the DNA and RNA content of the cells - is observed. Interestingly, these results are in agreement with what found by Notingher and colleagues through Raman experiments [20,21]. Indeed, they showed that ES undifferentiated cells have a higher RNA content than differentiating cells, suggesting that the decrease in intensity of the RNA response can be taken as a marker of the ES cell differentiation status. 


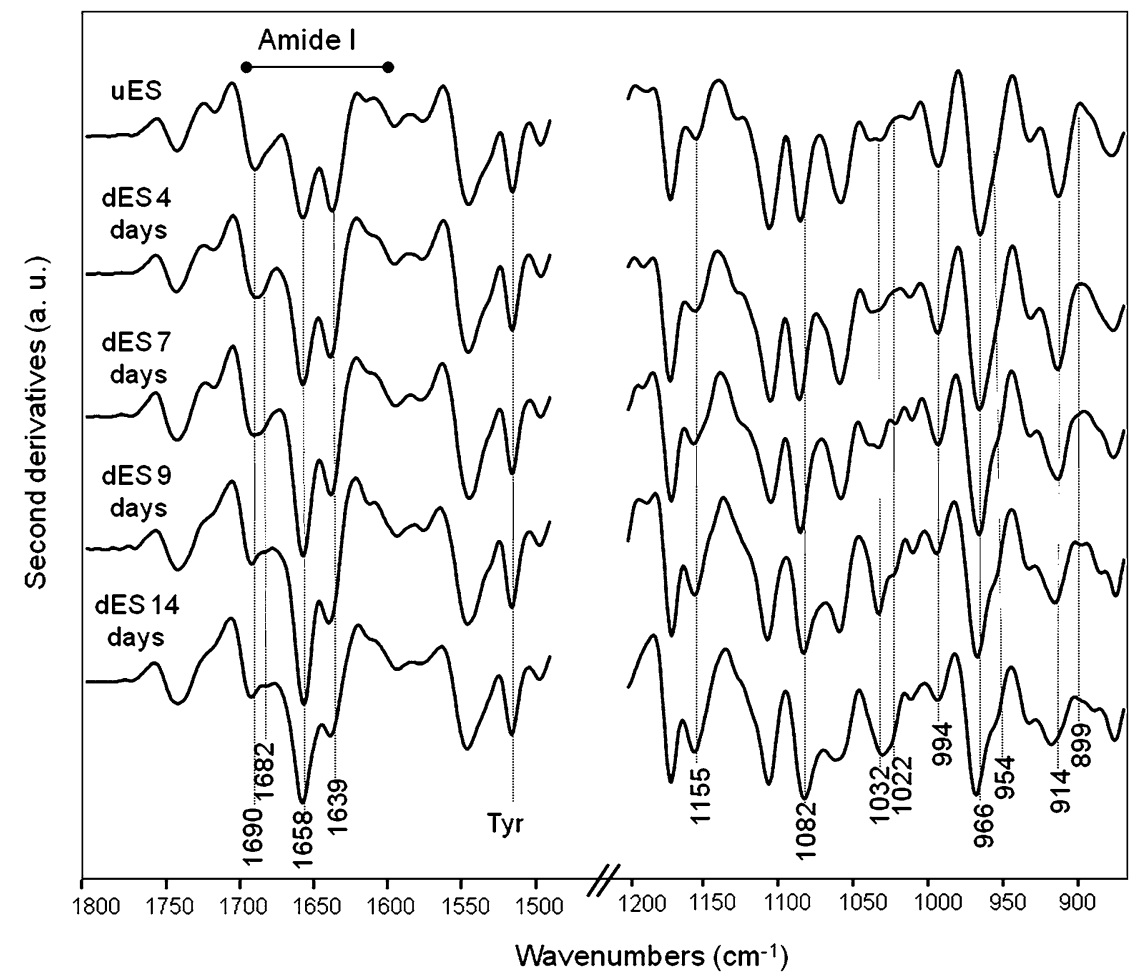

Fig. 1. Second derivative FT-IR spectra of undifferentiated and differentiating ES cells. Second derivative FT-IR spectra of ES cells undifferentiated and at different stages of differentiation are reported in the protein and in the nucleic acid absorption regions. Spectra have been normalized at the tyrosine band around $1515 \mathrm{~cm}^{-1}$. In the region $1050-850 \mathrm{~cm}^{-1}$ the intensity of the spectra is magnified by a factor three.

As differentiation proceeds (between day 4 and 7), a minor shoulder of the $966 \mathrm{~cm}^{-1}$ band becomes apparent around $954 \mathrm{~cm}^{-1}$. This last component (due to the CC stretching of DNA backbone), together with the rising of a band at $899 \mathrm{~cm}^{-1}$ (assigned to a vibrational mode of A-DNA) [5], indicates the presence - after 4-7 days of differentiation - of a DNA/RNA hybrid, which is known to assume an A-DNA conformation [5]. At day 7 of differentiation, a new band appears at $969 \mathrm{~cm}^{-1}-$ following a decrease of the DNA band at $966 \mathrm{~cm}^{-1}$ - that can be assigned to RNA ribose phosphate main chain [5].

These findings are consistent with the temporal response of the cell proteins discussed above and indicate that, between day 4 and 7 , the transcription of the genome takes place, followed by the expression of the proteins of the new phenotype.

We should add that in the nucleic acid spectral region we observed also the absorption bands of glycogen around 1032 and $1022 \mathrm{~cm}^{-1}$ (C-O-H bending), $1081 \mathrm{~cm}^{-1}$ (C-C stretching) and $1154 \mathrm{~cm}^{-1}$ (C-O stretching) [30], whose intensities increase starting at day 7 of differentiation (Fig. 1). Interestingly, this result indicates the emergence of a cell population rich in glycogen, in agreement with the PAS reaction experiments that proved the presence of cardiomyocyte precursors.

\subsection{FT-IR response of differentiating ES cells in the $3050-2800 \mathrm{~cm}^{-1} \mathrm{CH}_{2} / \mathrm{CH}_{3}$ absorption region}

It has been recently suggested that lipid changes could be indicators of the ES cell status, tagging proliferation, differentiation and apoptosis [12]. Even if the understanding of the lipid role is funda- 
mental to the knowledge of these physiological processes, at present very little is known at this regard.

To get new insights on lipid variations during ES cell differentiation, we analyzed the infrared response of undifferentiated and differentiating ES cells in the $3050-2800 \mathrm{~cm}^{-1}$ region, mainly due to the $\mathrm{CH}_{2}$ and $\mathrm{CH}_{3}$ acyl chain vibrations $[2,10,18]$.

As shown in Fig. 2, the $\mathrm{CH}_{2}$ bands at 2923 and at $2852 \mathrm{~cm}^{-1}$ - sensitive to hydrocarbon chain conformation [18] - increase as soon as the differentiation process starts (day 0-4), growing again after day 7 up to the end of our observation (9-14 days). These results indicate that during the first stages of the ES cell differentiation process changes in the lipid composition take place, suggesting that the starting of the differentiation can be monitored by the lipid infrared response.

It should be also noted that in the early stages of differentiation (up to 4 days) the band at $2923 \mathrm{~cm}^{-1}$, due to the asymmetric stretching of $\mathrm{CH}_{2}$, displays a prominent shoulder around $2936 \mathrm{~cm}^{-1}$ that markedly decreases up to day 7 (see the inset of Fig. 2). This last component can be assigned to methyl group vibrations as suggested by Lewis and McElhaney [18]. At the same times, also the methyl absorption band at $2873 \mathrm{~cm}^{-1}$ decreases in intensity. We believe that the changes in the $2936 \mathrm{~cm}^{-1}$ shoulder could reflect variations in the methylation levels of stem cell DNA and histones during differentiation $[7,14]$. This result, if confirmed by molecular biology assays on the examined ES cells, could be of particular relevance, considering the role played by the methyl groups dynamics in all the biological phenomena governed by epigenomic changes regulating gene expression.

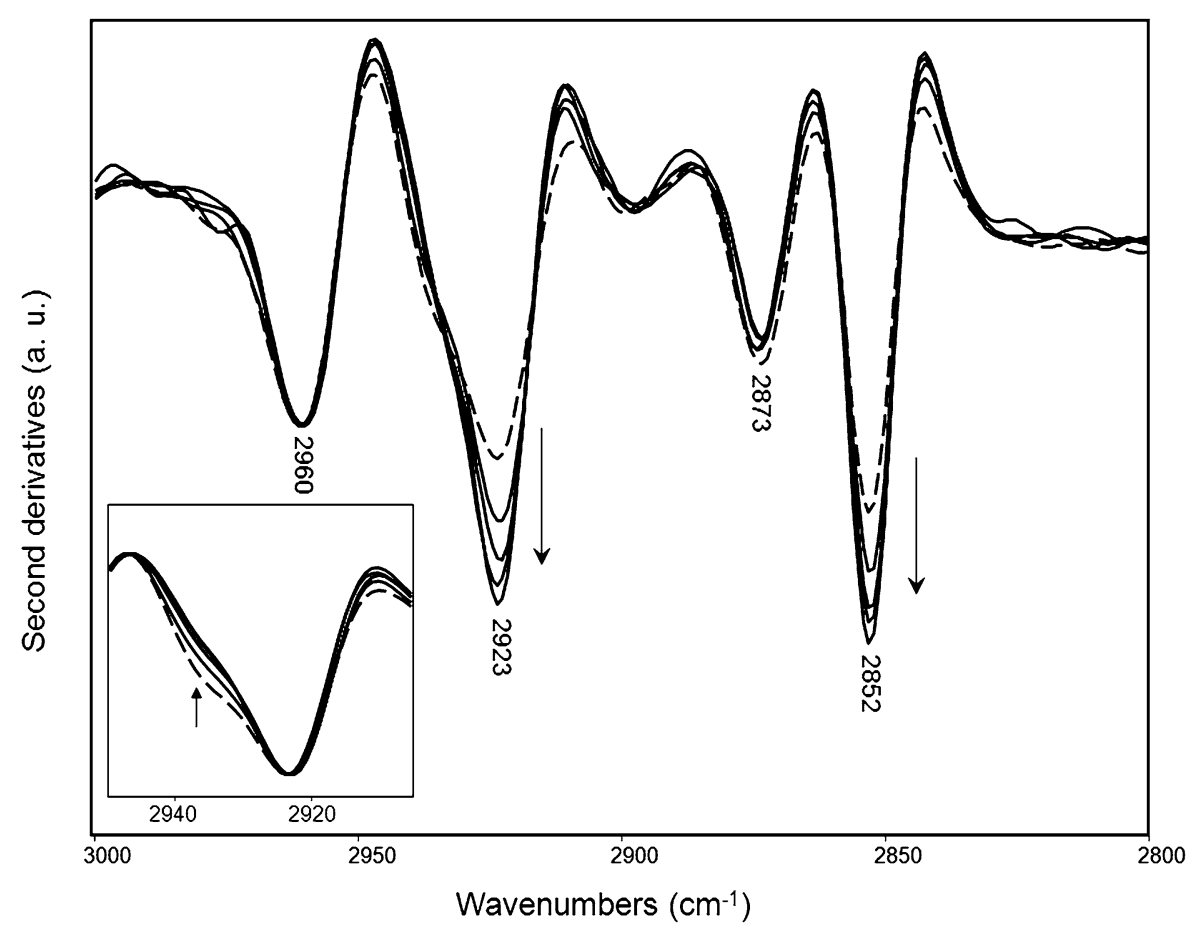

Fig. 2. Changes in the $\mathrm{CH}_{2}$ and $\mathrm{CH}_{3}$ absorptions during ES cell differentiation. Second derivative FT-IR spectra - normalized at the $2960 \mathrm{~cm}^{-1} \mathrm{CH}_{3}$ stretching - of ES cells undifferentiated (dashed line) and at days 4, 7, 9 and 14 (continuous lines) of differentiation. In the inset, a magnification of the band around $2923 \mathrm{~cm}^{-1}\left(\mathrm{CH}_{2}\right.$ stretching) is reported after normalization at the maximum intensity to better appreciate the shoulder around $2936 \mathrm{~cm}^{-1}$. Arrows point in the direction of increasing differentiation times. 


\subsection{PCA-LDA analysis}

To validate our spectroscopic results, we performed the PCA-LDA analysis [11,29] that allowed to identify the most significant spectral changes occurring during the ES cell differentiation process and to segregate into separated clusters the different stages of differentiation.

The analysis was performed in the spectral region between 1800 and $800 \mathrm{~cm}^{-1}$, where the protein and nucleic acid absorption is found. Measured absorption, first and second derivative spectra were used as input for the analysis. In all cases, an excellent segregation of the data into 5 different clusters - each corresponding to a specific differentiation stage - was obtained [4], as shown in Fig. 3(A) where the twoand three-dimensional plots of PCA-LDA performed on the second derivatives are reported. Also, this

A
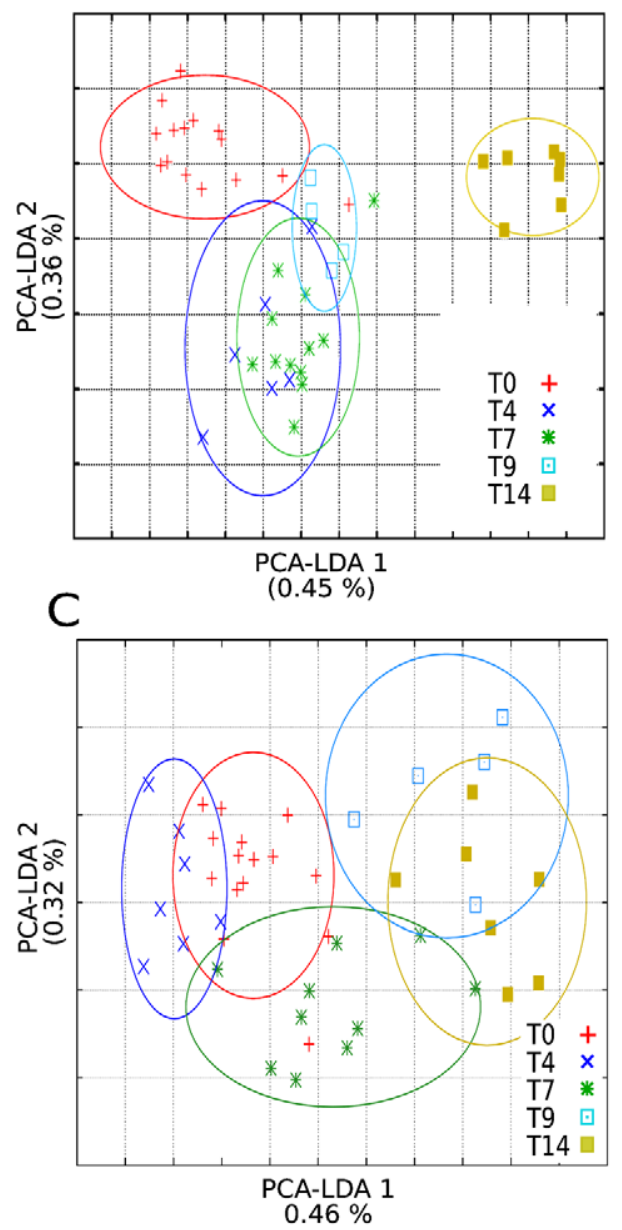

B
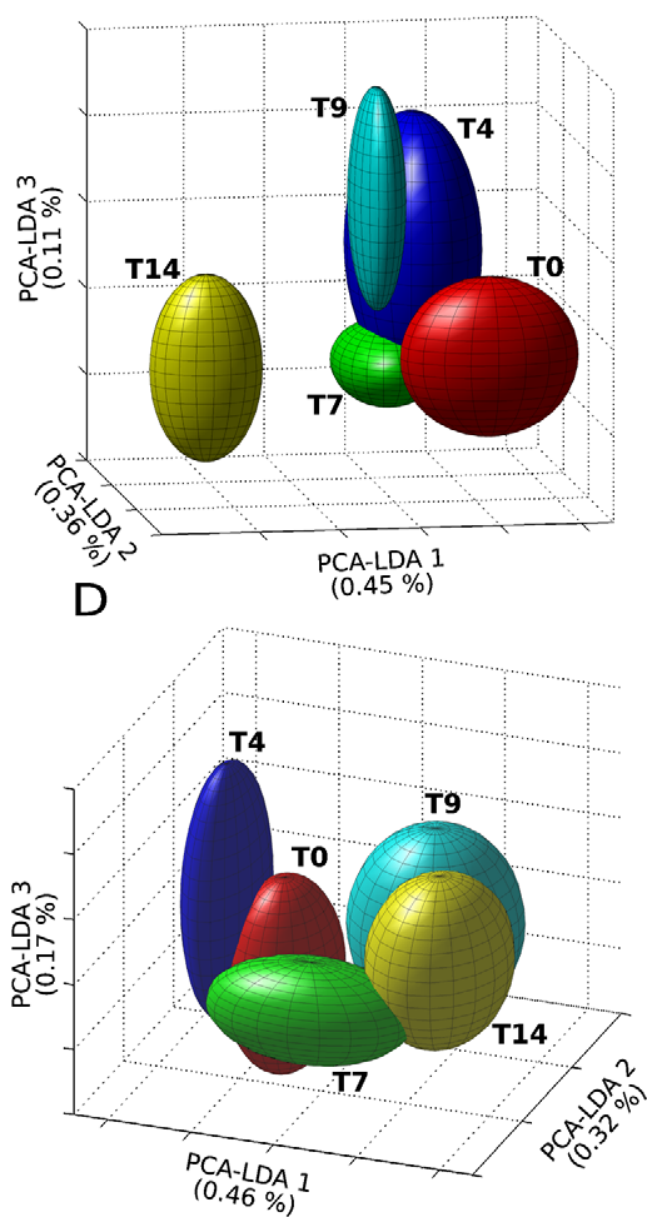

Fig. 3. PCA-LDA of ES cell differentiating second derivative spectra. Clustering of second derivative spectra from 1800 to $800 \mathrm{~cm}^{-1}$ is reported as 2D (A) and 3D (B) score plots. Clustering of second derivative spectra in the lipid absorption region from 3050 to $2800 \mathrm{~cm}^{-1}$ : 2D (C) and 3D (D) score plots. On each PCA-LDA component, the percentage of the explained variance is reported. Represented data correspond to 4, 7, 9 and 14 days of differentiation. Clusters are represented as ellipses in the $2 \mathrm{D}$ plot and ellipsoids in the 3D. The semi-axes of ellipses/ellipsoids in the 2D/3D plots correspond to two standard deviations of the data. 
analysis enabled us to find the wavenumbers in the spectrum that contribute to the largest inter spectral variance [29], validating the identification of the marker bands of ES cell differentiation obtained by the direct inspection of the spectral data, discussed in the previous paragraphs. In Table 1 the wavenumbers with the highest loadings to the inter-spectral variance are reported.

In addition, we performed the PCA-LDA analysis of the second derivative spectra in the lipid absorption region between 3050 and $2800 \mathrm{~cm}^{-1}$ (Fig. 3(B)). The clusters of the cell spectra at times 0 and 4 days of differentiation are well separated from those at 9 and 14 days, while the cluster at 7 days is partially overlapped with the other two clusters.

All these results are in agreement with what found by the direct inspection of the spectral data and confirmed by biological assays. In particular, the temporal evolution of the marker bands of the ES cell differentiation process indicates that, between days 4 and 7, the transcription of RNA takes place, followed by the synthesis of the proteins of the new phenotype. Indeed, the most significant marker bands of differentiation were found to be due to nucleic acid components (see Table 1). In addition, the emergence of the absorption due to glycogen - evident at day 7 - confirms the appearance of the new cell type (cardiomyocyte precursors).

\subsection{Conclusive remarks}

As conclusive remark, this study highlights the potential of FT-IR spectroscopy - supported by the PCA-LDA analysis - to identify the marker bands of the ES cell differentiation. The temporal evolution of these marker bands allows to follow in situ the progress of the process through the simultaneous monitoring of the most important cellular components. Interestingly, the infrared response that we suggest could be due to changes in methylation during differentiation opens the unexplored possibility of exploiting the potential of FT-IR spectroscopy to detect methyl groups dynamics in epigenomics studies.

\section{Acknowledgements}

Silvia Maria Doglia acknowledges the financial support of F.A.R. (Fondo d'Ateneo per la Ricerca) grants. Carlo Alberto Redi acknowledges the financial support of Ricerca Corrente 2009 by Fondazione IRCCS Policlinico San Matteo, Pavia (Italy).

\section{References}

[1] D. Ami, A. Natalello, A. Zullini and S.M. Doglia, Fourier transform infrared microspectroscopy as a new tool for nematode studies, FEBS Lett. 576 (2004), 297-300.

[2] D. Ami, A. Natalello, T. Schultz, P. Gatti-Lafranconi, M. Lotti, S.M. Doglia and A. de Marco, Effects of recombinant protein misfolding and aggregation on bacterial membranes, BBA-Proteins Proteom. 1794 (2009), 263-269.

[3] D. Ami, A. Natalello, G. Taylor, G. Tonon and S.M. Doglia, Structural analysis of protein inclusion bodies by Fourier transform infrared microspectroscopy, BBA-Proteins Proteom. 1764 (2006), 793-799.

[4] D. Ami, T. Neri, A. Natalello, P. Mereghetti, S.M. Doglia, M. Zanoni, M. Zuccotti, S. Garagna and C.A. Redi, Embryonic stem cell differentiation studied by FT-IR spectroscopy, BBA-Mol. Cell Res. 1783 (2008), 98-106.

[5] M. Banyay, M. Sarkar and A. Graslund, A library of IR bands of nucleic acids in solution, Biophys. Chemist. 104 (2003), $477-488$.

[6] A. Barth and C. Zscherp, What vibrations tell us about proteins, Q. Rev. Biophys. 35 (2002), 369-430.

[7] T. Burgold, F. Spreafico, F. De Santa, M.G. Totaro, E. Prosperini, G. Natoli and G. Testa, The histone H3 lysine 27-specific demethylase Jmjd3 is required for neural commitment, PLoS One 3 (2008), e3034. 
[8] J.W. Chan and D.K. Lieu, Label-free biochemical characterization of stem cells using vibrational spectroscopy, J. Biophotonics 2 (2009), 656-668.

[9] L.P. Choo, D.L. Wetzel, W.C. Halliday, M. Jackson, S.M. LeVine and H.H. Mantsch, In situ characterization of betaamyloid in Alzheimer's diseased tissue by synchrotron Fourier transform infrared microspectroscopy, Biophys. J. 71 (1996), 1672-1679.

[10] I. Echabe, M.A. Requero, F.M. Goni, J.L. Arrondo and A. Alonso, An infrared investigation of palmitoyl-coenzyme A and palmitoylcarnitine interaction with perdeuterated-chain phospholipid bilayers, Eur. J. Biochem. 231 (1995), 199-203.

[11] T. Fearn, Discriminant analysis, in: Handbook of Vibrational Spectroscopy, J.M. Chalmers and P.R. Griffiths, eds, Wiley, New York, 2002, pp. 2086-2093.

[12] B. Fuchs, J. Schiller, R. Süß, M. Zscharnack, A. Bader, P. Müller, M. Schürenberg, M. Becker and D. Suckau, Analysis of stem cell lipids by offline HPTLC-MALDI-TOF MS, Anal. Bioanal. Chem. 392 (2008), 849-860.

[13] O. Grude, T. Nakamura, A. Hammiche, A.J. Bentley, F.L. Martin, H.M. Pollock, S. Kinoshita and N.J. Fullwood, Discrimination of human stem cells by photothermal microspectroscopy, Vibr. Sprectrosc. 49 (2009), 22-27.

[14] I. Hatada, S. Morita, M. Kimura, T. Horii, R. Yamashita and K. Nakai, Genome-wide demethylation during neural differentiation of P19 embryonal carcinoma cells, J. Hum. Genet. 53 (2008), 185-191.

[15] J. Heo, J.S. Lee, I.S. Chu, Y. Takahama and S.S. Thorgeirsson, Spontaneous differentiation of mouse embryonic stem cells in vitro: characterization by global gene expression profiles, Biochem. Biophys. Res. Commun. 332 (2005), 1061-1069.

[16] P. Heraud and M.J. Tobin, The emergence of biospectroscopy in stem cell research, Stem Cell Res. 3 (2009), 12-14.

[17] P.H. Lerou and G.Q. Daley, Therapeutic potential of embryonic stem cells, Blood Rev. 19 (2005), 321-331.

[18] R.N.A.H. Lewis and R.N. McElhaney, Fourier transform infrared spectroscopy in the study of lipid phase transitions in model and biological membranes: practical considerations, Methods Mol. Biol. 400 (2007), 207-226.

[19] F.L. Martin and H.M. Pollock, Microspectroscopy as a tool to discriminate nano-molecular cellular alterations in biomedical research, in: Oxford Handbook of Nanoscience and Technology 2, A.V. Narlikar and Y.Y. Fu, eds, Oxford University Press, Oxford, 2009, pp. 285-336.

[20] I. Notingher, I. Bisson, A.E. Bishop, W.L. Randle, J.M.P. Polak and L.L. Hench, In situ spectral monitoring of mRNA translation in embryonic stem cells during differentiation in vitro, Anal. Chem. 76 (2004), 3185-3193.

[21] I. Notingher, I. Bisson, J.M. Polak and L.L. Hench, In situ spectroscopic study of nucleic acids in differentiating embryonic stem cells, Vibr. Sprectrosc. 35 (2004), 199-203.

[22] F. Orsini, D. Ami, A.M. Villa, G. Sala, M.G. Bellotti and S.M. Doglia, FT-IR microspectroscopy for microbiological studies, J. Microbiol. Methods 42 (2000), 17-27.

[23] Y. Oyamada, K. Komatsu, H. Kimura, M. Mori and M. Oyamada, Differential regulation of gap junction protein (connexin) genes during cardiomyocytic differentiation of mouse embryonic stem cells in vitro, Exp. Cell Res. 229 (1996), 318-326.

[24] K.B.S. Pasumarthi and L.J. Field, Cardiomyocyte enrichment in differentiating ES cell cultures: strategies and applications, in: Embryonic Stem Cells Methods and Protocols, K. Turksen, ed., Humana Press, Totowa, NJ, 2002, pp. 157-168.

[25] A.G. Smith, Embryo-derived stem cells: of mice and men, Annu. Rev. Cell Dev. Biol. 17 (2001), 435-462.

[26] H. Susi and D.M. Byler, Resolution-enhanced Fourier transform infrared spectroscopy of enzymes, Methods Enzymol. 130 (1986), 291-311.

[27] K. Thumanu, W. Tanthanuch, C. Lorthongpanich, P. Heraud and R. Parnpai, FT-IR microspectroscopic imaging as a new tool to distinguish chemical composition of mouse blastocyst, J. Mol. Struct. 933 (2009), 104-111.

[28] M.J. Walsh, A. Hammiche, T.G. Fellous, J.M. Nicholson, M. Cotte, J. Susini, N.J. Fullwood, P.L. Martin-Hirsch, M.R. Alison and F.L. Martin, Tracking the cell hierarchy in the human intestine using biochemical signatures derived by midinfrared microspectroscopy, Stem Cell Res. 3 (2009), 15-27.

[29] M.J. Walsh, M.N. Singh, H.M. Pollock, L.J. Cooper, M.J. German, H.F. Stringfellow, N.J. Fullwood, E. Paraskevaidis, P.L. Martin-Hirsch and F.L. Martin, ATR microspectroscopy with multivariate analysis segregates grades of exfoliative cervical cytology, Biochem. Biophys. Res. Commun. 352 (2007), 213-219.

[30] T.D. Wang, G. Triadafilopoulos, J.M. Crawford, L.R. Dixon, T. Bhandari, P. Sahbaie, S. Friedland, R. Soetikno and C.H. Contag, Detection of endogenous biomolecules in Barrett's esophagus by Fourier transform infrared spectroscopy, PNAS 104 (2007), 15864-15869. 


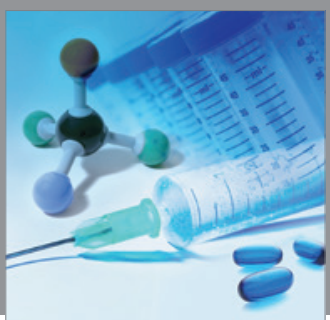

International Journal of

Medicinal Chemistry

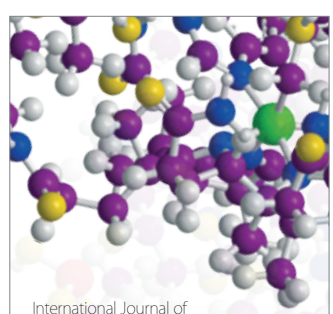

Carbohydrate Chemistry

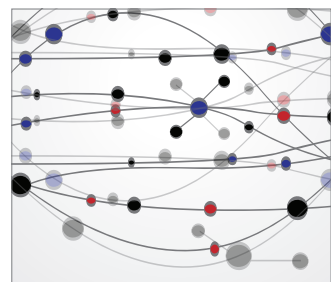

The Scientific World Journal
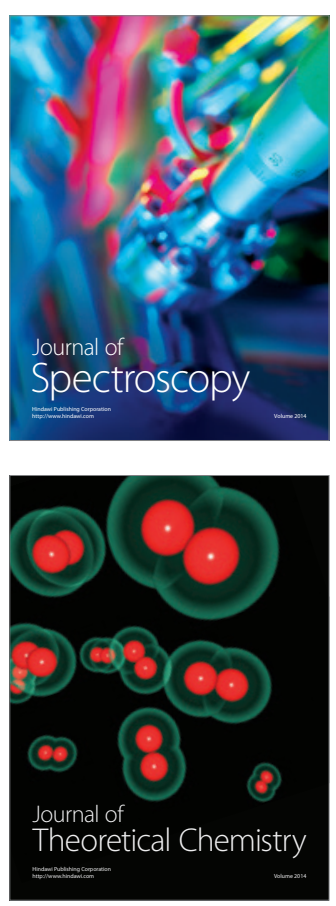
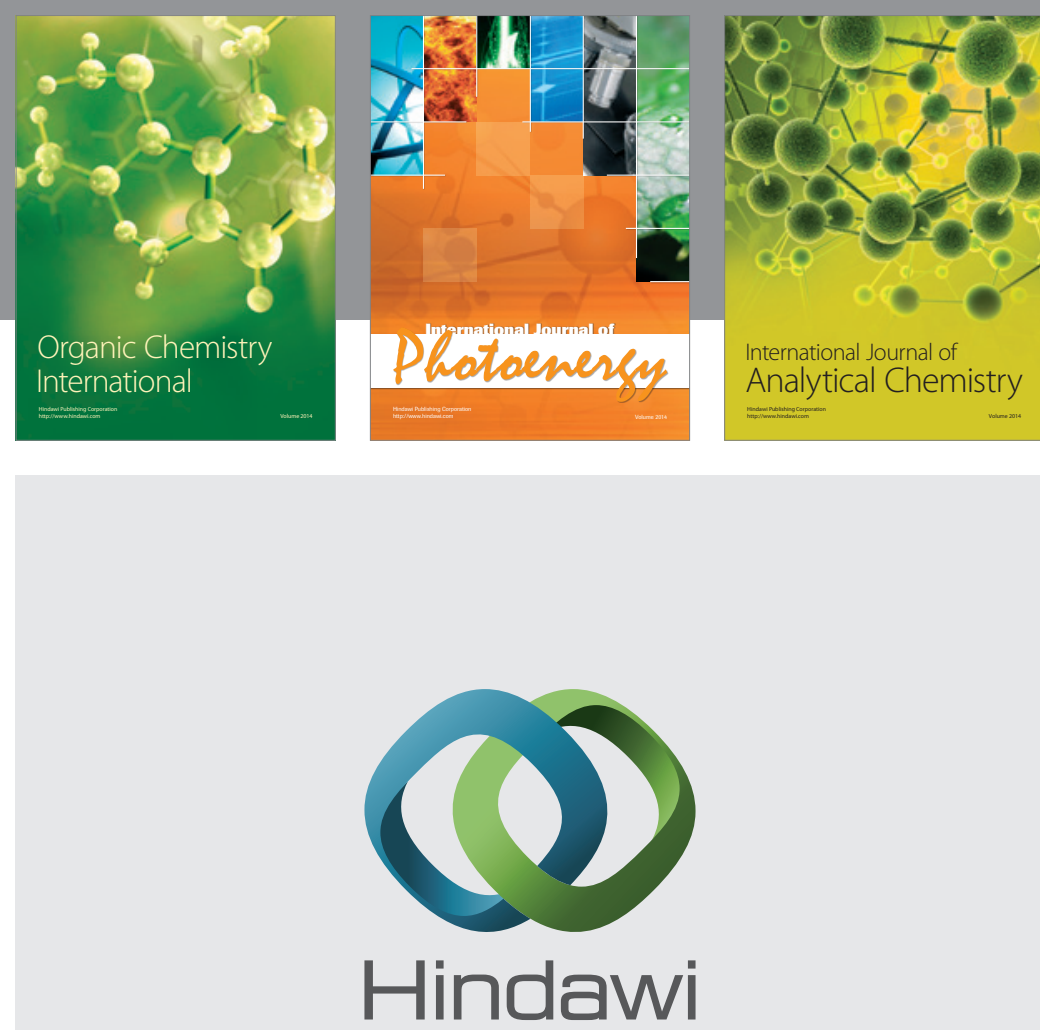

Submit your manuscripts at

http://www.hindawi.com
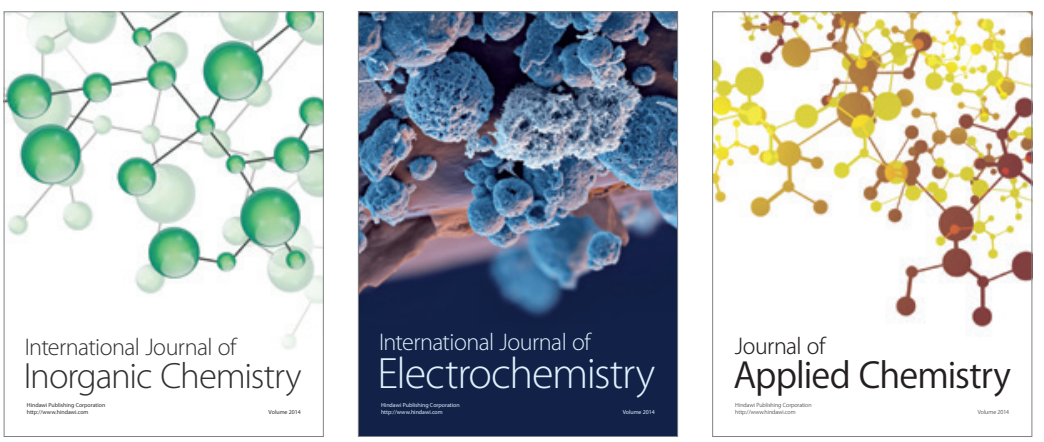

Journal of

Applied Chemistry
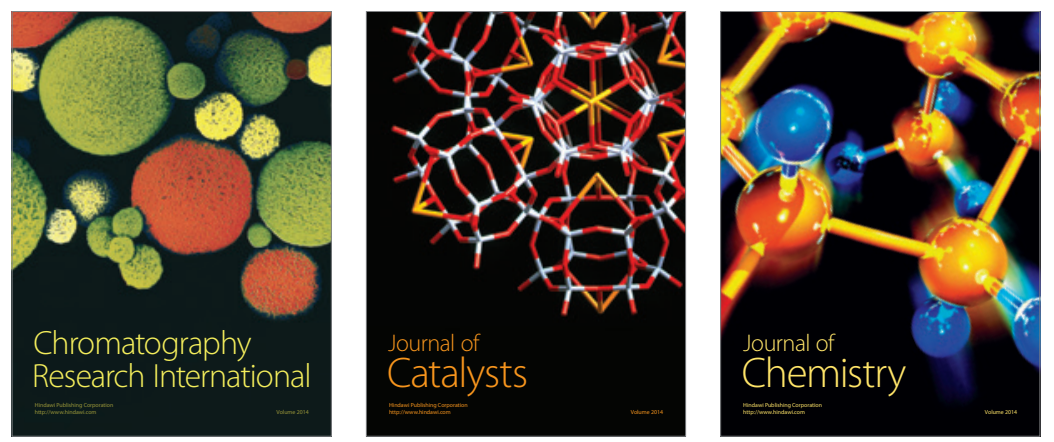
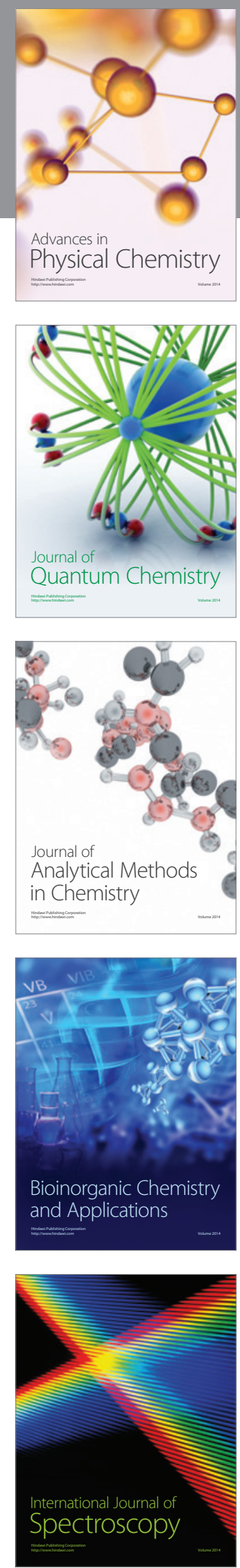